\title{
Parental Beliefs and Children's Metacognitive Awareness
}

\section{Nina Marliyani ${ }^{\mathrm{a}}$ and Sri Hartati R. Suradijono}

${ }^{a}$ Developmental Psychology Department, Faculty of Psychology, Universitas Indonesia, Depok, Indonesia; ${ }^{b}$ Developmental Psychology Department, Faculty of Psychology, Universitas Indonesia, Depok, Indonesia

*Corresponding author:

Sri Hartati R. Suradijono

Department of Developmental Psychology,

Faculty of Psychology, Universitas Indonesia

Jl. Lkr. Kampus Raya, Depok, Jawa Barat

Indonesia, 16424

Tel.: +62 217270004

Email: hartati@ui.ac.id / hartati_reksur@yahoo.com 


\title{
Parental Beliefs and Children's Metacognitive Awarenes
}

\begin{abstract}
Metacognition is the knowledge a person has of his or her thinking and of things related to that thinking process (Flavell, 1979). Children with metacognitive awareness have better self-management and time and activity management (Brown \& Smiley, 1978; Schraw \& Dennison, 1994). Parents' beliefs and behavior influence their children's cognitive development (S. Miller 1988; Carr et al, 1989). The aim of this study determines the influence of parental beliefs on children's metacognitive awareness. This study has a quantitative design, incorporating a self-report questionnaire, namely the Parental Beliefs Questionnaire (PBQ) or the Junior Metacognitive Awareness Inventory (Jr. MAI), depending on surveyed population. The participants are 64 parents and 64 students in the fourth grade from three schools. The results of PBQ regression analysis undertaken on the results of Jr. MAI do not show a significant relationship, with a significance-test value of 0.742 . For further research, first, addition of participant is needed; second, addition of variables such as teacher beliefs and parental behavior may be needed in the next study.
\end{abstract}

Keywords: parental belief, children's metacognitive awareness

\section{Introduction}

This Psychologists have been researching metacognition since the 1970s (Brown \& Smiley, 1978; Flavell, 1979). Metacognition is important for understanding human thinking. According to Flavell (1979), some researchers have concluded that metacognition plays a major role in language learning and verbal abilities, including communication, persuasion, and understanding; problem solving; memory; social thinking; and self-control and selfdirectedness.

Metacognition is also used to classify high-level cognitive abilities that allow humans to observe their own thinking and improve its outcomes through knowledge of its strengths and limitations (Kim, Zyromsid, Mariani, Min Lee, \& Carey, 2017). Brown and Smiley (1978) found two types of metacognition: knowledge of cognition and the regulation of cognition. First, knowledge of cognition refers to the way that individuals understand their memory and how they learn. Knowledge of cognition includes three types of metacognitive awareness, namely, declarative, procedural, and conditional knowledge (Brown, 1987). Second, the regulation of cognition refers to regulation of memory and learning. Included in this regulation are planning, monitoring, and evaluating thinking and learning (Schraw \& Dennison, 1994).

Research shows that students who have metacognitive awareness use learning strategies and enjoy superior results to those who do not have metacognitive awareness (Garner \& Alexander, 1989). Metacognitive awareness allows individuals to plan, sequence, and monitor their learning, which can ultimately improve their outcomes (Shraw \& Dennison, 1994). Brown and Smiley (1978) found that children with metacognitive abilities achieve better learning outcomes, through their knowledge of and control over their thinking. Metacognitive 
development forms part of school curricula in the United States in school consultant programs such as the Student Success Skills Curriculum (SSS Curriculum) in 2007, and the ASCA (American School Counselor Association) Mindset and Behavior for Student Success, published in 2014 (Kim et al, 2017). The essence of such curricula is teaching children to develop their cognitive, social, and self-management skills to an optimal point. Subsequent research has shown that the SSS Curriculum is related to improvements in students' metacognitive skills and academic achievements (Lemberger, Selig, Bowers, \& Rogers, 2015). Mohtari and Reichard (2002) showed that metacognitive skills are associated with reading ability. Students with metacognitive awareness show optimal learning results. Veenman and Spaans (2004) studied the relationship between the intelligence and metacognitive abilities of seventh and ninth graders as displayed in their work on math assignments. Their results show that for both age groups, metacognitive abilities can predict the results of work.

Researchers and practitioners believe that metacognition plays a critical role in memory, learning, and student achievement (Sperling, Richmond, Ramsay, \& Klapp, 2012). The results of Sperling et al. (2012) located an important role for metacognition in student achievement in science, providing evidence that metacognition is a significant predictor of achievement in science and overall learning achievement, as measured by using the cumulative achievement index.

Metacognition, the ability to reflect, understand, and control learning (Schraw \& Dennison, 1994) requires to be studied and developed with reference to the age of the individual in question (Flavell, 1979). Brown (1997) held that it is illegitimate to expect children to exhibit high-level thinking, except where the adults around them involve children in meaningful learning, rich in experience, with specific subjects.

The adults who are best placed to facilitate the development of the cognitive and metacognitive abilities of children are those who are closest, namely, their parents. According to Vgotsky (cited in Fox \& Riconscente, 2008), metacognition and self-regulation must be placed within the broad continuum of human activity and at all stages of human development. Interactions that encourage metacognitive development and self-regulation occur first in the home environment; that is, parents, through the use of language, act as psychological cultural tools. Language has historical and cultural roots in community groups. In line with Bronfrenbrenner's theory (P. H. Miller, 2011), culture at the macro level indirectly influences individual development by forming the mindset and behavior of society, including parents. Culture at micro level will affect how parents raise their children. Thus, it can be said that parenting behavior is influenced by culture, which forms parental belief systems and shows parental behavior. At a macro level, the influence of the policies of the central government influence children's cognitive and metacognitive development in the form of policies in education.

Parents' thinking regarding belief is an interesting research topic in adult social cognition. Parental thinking has also been explored in relation to the effects of parents' thinking on their behavior and child development (Miller, Manhal, \& Mee, 1991). Miller et al. (1991) studied 
the beliefs parents have on their children's cognitive development, in particular, accuracy of parental beliefs, namely the accuracy of the beliefs in the cognitive abilities of their children (in this case second and fifth graders). One of the results of this study was to find a positive relationship between parental accuracy and child performance. Parents who believe that their children are able to perform research assignments have child who demonstrate abilities in accordance with the beliefs of parents. This is explained by the supposition that the parents who understand their children's abilities are become more sensitive and responsive in rearing and teaching their children.

Aunola, Nurmi, Niemi, Lerkkanen and Rasku-Puttonen (2002) in their research stated that parental beliefs play an important role in academic performance. They examined the relationship between parental belief on the performance of children in school, children's strategies for achievement, and the way first grade students gained literacy. The results of this study showed that the beliefs of both parents on their children's general competency in school could predict strategies for achievement to support the children's reading performance. Okagaki and Sternberg (1993) researched the effects of parental beliefs on their children's learning achievements and found evidence that culture plays a significant role in the formation of parental beliefs, with an emphasis on child rearing that encourages the children to be independent and inculcate concepts of intelligence and educational goals. Parents who believe that children must be taught independence and can adapt to their environment, parents with a conception of intelligence that includes cognitive and non-cognitive aspects, and parents who understand educational goals and what teachers' duties at school can help children increase their metacognitive abilities.

The importance of the relationship between parental belief and children's performance at school has been widely studied (Aunola et al., 2002; Okagaki \& Sternberg, 1993; Galper, Wigfield \& Seefeldt, 1997; Miller et al. 1991, etc.). Study of the importance of metacognition to improving achievement and children's learning has also been performed (Brown \& Smiley, 1978; Flavell, 1979; Shcraw \& Dennison, 1994; Kim et al, 2017; Mohtari \& Reichard, 2002; Veenmaan \& Spaans 2004). Study of the relationship between parental belief and metacognition is relatively rare.

Children develop in proximal relationships (Tudge, Mokrove, Hatfield, \& Karnik, 2009) with parents, such that the parents' beliefs as embodied in their parenting behavior, can affect the children's development (S. Miller, 1988). In this study, fourth-grade students, generally 10 years old, and the beliefs of their parents are investigated. Fourth-grade students are selected because that period of development marks the end of concrete operational cognitive growth (Crain, 2013), meaning that the child has a relatively mature brain. In adolescence, of course, cognition again begins to develop (Steinberg, 2005). The importance of metacognition as a basis for children's life skills development has been found in previous studies (Kim et al., 2017; Mohtari \& Reichard, 2002; Veenmaan \& Spaans, 2004). However, no strong predictor for the development of children's metacognitive abilities has yet been found. This study will help find an association between parental beliefs and the development of children's metacognitive awareness as well as developing the kind of child rearing that is needed. In 
addition, knowledge of the importance of children's metacognitive awareness will help schools and parents design appropriate teaching methods for children. The study is conducted at three private schools in the area of Depok, Indonesia, selected according with the consideration that parents who send their children to these schools have specific beliefs and goals for their children's education. These private schools are different from public schools in several ways. Each class has only 25 students, while in local public schools, as many as 48 students are found in one class. These schools also use active learning methods, while public schools generally adopt one-way methods. Furthermore, private schools are able to offer more hours of instruction than public schools can. So the study try to capture these differences and to see whether these conditions support student thinking, especially their metacognitive awareness.

\section{A. Metacognitive Awareness}

Young (2003) concluded, using the results of Flavell (1979) and Brown (1979), that metacognitive awareness is awareness that a person has about things known or understood, difficulties encountered, and present affective conditions. Wilson and Crack (2004) added the element of the ongoing mental processes of a person the position or place someone is in how engages in learning activities. Schraw and Dennison (1994) argued that metacognitive awareness is a person's knowledge of his own metacognition.

\section{B. Parental Beliefs}

According to McGillicuddy-DeLisi (1980), parental beliefs are tools or conceptions used by parents to support their actions and direct their behaviors. What parents believe about their children's development in general and children's capabilities in particular form the basis for their parenting practices. In this study parental beliefs regard the specific abilities of their children (Okagaki \& Sternberg, 1993), namely, child rearing, or parenting with an emphasis on autonomy and conformity, consisting of parental behaviors that support problem-solving skills, creativity, practical skills, and conformity; conception of Intelligence, which shapes how parents view the intelligence of their children, divided into two, cognitive, that is, problem solving, verbal, and creative skills, and non-cognitive skills, such as self-management skills, social skills, and motivation to learn; educational goals, or parents' views on the outcomes of learning and what teachers should teach students.

\section{Methods}

\section{Research Design}

This research is an explorative study with a quantitative design. The independent variable is parental belief in child rearing, which concern their ideas of children's autonomy, concepts of intelligence, and educational goals as the dependent variable, namely, metacognition awareness, which is the knowledge and regulation of cognition, among fourth-grade students. The research hypotheses are, first, there is a significant relationship between parental beliefs and metacognitive awareness of fourth grade; second, parental beliefs have an influence on children's metacognitive awareness. 


\section{Participants}

The participants in this study were 64 fourth-grade students studying at three private schools and one parent, either father or mother, for each student, in Depok, Indonesia. The gender of the child participants was nearly balanced between male and female. The sample was chosen by convenience sampling.

\section{Measurement Methods}

Parental beliefs were measured using the Parental Beliefs Questionnaire (PBQ) developed by Okagaki \& Sternberg (1993). PBQ has three dimensions that measure parental beliefs on child rearing, concepts of intelligence, and educational goals, with a section of demographic questions. This scale was adapted by Shelva (2017, study in progress), and with her permission it was used in this study. Cronbach's alpha for the PBQ Scale is 0.95 for 64 items.

\section{Results}

\section{Data Collection}

The data were collected at three time points, in 2017 and 2018. A metacognitive awareness questionnaire for children was distributed, and it was completed after some remarks. The PBQ was entrusted to the child to take home, and the homeroom teachers were asked to remind the parents. The participants were 64 fourth grade students at three schools around Depok and 1 parent for each, father or mother. Three responses were not used due to omission of demographic data.

\section{Demographic Information}

The parents were 64 people, 9 fathers and 55 mothers. The average age of the parents was 40.6 years, and the most common highest levels of education completed were high school, academy and university. Thus, most parents have relatively high educational attainment. Most mothers were housewives, $59 \%$, and $34 \%$ were employees. The most common number of children in each family was 1-2 children, for 46\%, and 3-4 children, 31\%. There were 64 child participants, with an average age of 9.5 years, consisting of 29 boys and 35 girls in the fourth grade at a private elementary school.

\section{Test Result}

The reliability test results for the PBQ show a Cronbach's alpha value of 0.950 for the dimensions of $\mathrm{CR}$, the $\mathrm{CI}$ is 0.947 , and the EG is 0.827. So that it can be said that the reliability of PBQ measuring instruments is good. The reliability test for Jr. MAI gives 0.681 .

Table I. Descriptive Statistics

\begin{tabular}{|c|c|c|c|}
\hline & Mean & $\mathbf{N}$ & Total Score \\
\hline PBQ & 315 & 64 & 384 \\
\hline MAI & 29,5 & 64 & 36 \\
\hline
\end{tabular}

The range values for PBQ are between 64-384, with an average score of 315, indicating that most parents have good faith in childcare that encourages independence, intelligence including 
both cognitive and non-cognitive aspects, and the educational goals of schools. The average Jr. MAI score was also high, 29.5 out of a total score of 36, which indicated that most children had good metacognitive awareness. This appears to indicate that the chosen private schools' educational methods supported the idea of the development of children's metacognitive awareness.

Table II. Results of PBQ Regression Analysis for Jr. MAI Showing a Non-Significant Value of 0.742

\begin{tabular}{llll}
\hline Model & Std.Error & F & Sig \\
\hline Regression & .127 & .109 & .742 \\
Dependent Variabel (MAI) & & & \\
Predictors (Constant) (PBQ) & & & \\
\hline
\end{tabular}

Table III. Results of PBQ Dimension Regression Analysis on Dimension of Jr. MAI

\begin{tabular}{lcrrr}
\hline & Std.Error & \multicolumn{1}{c}{ Sig. } & Std. Error & Sig. \\
\hline CR & .149 & .703 & .151 & .800 \\
CI & .219 & .665 & .221 & .811 \\
EG & .213 & .290 & .215 & .788 \\
& Dependent Variable (KC) & Dependent Variable (RC) \\
\hline
\end{tabular}

Table 2 shows a significance of 0.742 , exceeding the given value of 0.05 . Table 3 also shows a significance value for each parental belief dimension, CR (child rearing, parenting), CI (conception of intelligence), and EG (educational goals) each having values of more than 0.05. This can be interpreted to mean that in general, parental belief in the aspects of CR, CI, and EG have little influence on children's metacognitive abilities, in this case their metacognitive awareness. Table 3 shows the calculations for each dimension of parental belief with regard to their children's metacognitive awareness with the dimensions of regulation of cognition and $\mathrm{KC}$ (knowledge of cognition). The results show the figures of 0.703 and 0.800 with regard to the $\mathrm{CR}$ or parenting dimensions that encourage autonomy towards children's metacognitive awareness in two dimensions of $\mathrm{KC}$ and $\mathrm{RC}$, indicating that there is no influence of child rearing on children's autonomy on their metacognitive awareness, or more specifically, non their knowledge of cognition and regulation of it. The results for the CI dimension of are 0.685 for $\mathrm{KC}$ and 0.811 for $\mathrm{RC}$, which means that it is not significant, and there is no relationship between the conceptions of intelligence possessed by the parents on children's metacognitive awareness. Likewise, with the EG dimension, beliefs held by parents do not have a relationship with children's metacognitive awareness, as indicated by the significance levels of 0.213 (KC) and 0.788 (RC). Other factors have a stronger influence on children's metacognitive awareness and abilities.

\section{Discussion}

Predictors of the development of the children's metacognitive abilities remains understudied. The results of this study sought an association between parental beliefs and the development of child metacognitive awareness and to help indicate what kind of child rearing is most beneficial. In addition, knowledge of the importance of metacognitive awareness in children 
could help schools and parents to design appropriate teaching methods for their children at home and at school. Previous studies on parental belief and children's performance and of children's learning achievements at school have been performed (Aunola et al., 2002; Okagaki \& Sternberg, 1993; Galper et al., 1997), and the opinions of experts, such as Vygotsky, Piaget (Fox \& Riconscente, 2008) and Bronfenbrenner (P. H. Miller, 2011) on the importance of the influence of parents on children's cognitive development are widely known. Carr, Kurtz, Schneider, Turner, and Borkowski (1989) found that parents and teachers are can facilitate children's cognitive development by fostering their metacognition skills in instruction that provides space for children to think through an explanation of how things should be done and why they are needed. The instructions given by parents at home will shape the pattern and level of the speed of the child in carrying out a task. Because of the results of previous research and developmental theory, the authors consider that there is an influence of parental belief regarding child rearing, conception of intelligence, and educational goals, on the development of metacognitive awareness in children.

The results of this study are nonsignificant, in the sense that parental belief is not found to have an influence on children's metacognitive awareness. This nonsignificance may be due to several factors. First, the sample should be larger to ensure statistical power (Widhiarso, 2012): the larger the sample, the greater the strength of the statistical testing. Mediating factors also exist that appear between parental beliefs and children's metacognitive awareness, such as the teaching of the teachers, as indicated by Carr et al. (1989). Moey (1986) and Carr et al. (1989) illustrated that children's metacognitive knowledge is developed in school settings led by teachers, whereas parents provide the basis for metacognitive development before their children enter school (see also McCombs, 1986 in Carr et al., 1989).). Furthermore, parents' actual parenting behaviors are not part of this investigation; According to Miller (1988), parents' beliefs are important because they manifest in the behavior that affects children's cognitive development. To achieve the understanding of the effect of parental beliefs on children's metacognitive awareness, it is also necessary to include the variables of parenting behavior regarding children that encourage the development of children's metacognitive awareness.

\section{Conclusion}

Metacognition is a high-level thinking process where a person monitors his or her thinking independently (Flavell, 1979). Metacognition regards a person's knowledge of his or her thinking process and then regulating his thinking process (Brown, 1987). Many studies have shown that students with metacognitive awareness have additional strategies for problem solving and tasks and have better academic performance. Parents as caregivers and the people nearest to the development of the child have beliefs on that development in general and in specific (S. Miller, 1988). In cognitive development, parents play a role that is begins as belief. In this study, parental beliefs regarding child rearing, are related to autonomy, conception of intelligence, and educational goals. The influence of this on children's metacognitive awareness is significant. In the private schools in which this study was performed, the students indeed displayed good metacognitive awareness. 
The results of the study indicate no significant influence of parental belief in aspects of child rearing, conception of intelligence, or educational goals on children's metacognitive awareness, which raises several new research questions that demand further scientific exploration. The enlargement of the sample, taking into account the background of the respondent, and investigation of mediators or moderating factors, as well as and parents' concrete behaviors, may connect parental belief in aspects of care, conception of intelligence, and educational goals to children's metacognitive awareness. Thus, further research and a broader examination of the literature search are needed to explore the topic of parental belief and the metacognitive goals of children.

\section{References}

Aunola, K., Nurmi, J. E., Niemi, P., Lerkkanen, M. K., \& Rasku- Puttonen, H. (2002). Developmental dynamics of achievement strategies, reading performance, and parental beliefs. Reading Research Quarterly, 37(3), 310-327.

Bronfenbrenner, U. (2005). Making human beings human:Bioecological perpective of human devepoment. Thousand Oaks, CA: SAGE Publishing.

Brown, A. (1987). Metacognition, executive control, self-regulation, and other more mysterious mechanisms. In F. E. Wernert (Ed.), Metacognition, motivation, and understanding (pp. 65-116). Marwah, NJ: Erlbaum.

Brown, A. L., \& Smiley, S. S. (1978). The development of strategies for studying texts. Child Development, 49(4),1076-1088.

Brown, A. L. (1997). Transforming schools into communities of thinking and learning about serious matters. American psychologist, 52(4), 399.

Carr, M., Kurtz, B. E., Schneider, W., Turner, L. A., \& Borkowski, J. G. (1989). Strategy acquisition and transfer among American and German children: Environmental influences on metacognitive development. Developmental Psychology, 25(5), 765.

Crain, W. (2014). Theories of development : Concept and application (6 ${ }^{\text {th }}$ ed.). Essex: Pearson.

Efklides, A. (2006). Metacognition and affect: What can metacognitive experiences tell us about the learning process?. Educational Research Review, 1(1), 3-14.

Ennis, R.(1996). Critical thinking disposition: Their nature and assessability. Informal logic. Vol 18, no 2-3: 165-182.

Flavell, J. H. (1979). Metacognition and cognitive monitoring: A new area of cognitive-developmental inquiry. American psychologist, 34(10), 906.

Fox, E \& Riconscente, M. (2008). Metacognition and self-regulation in James, Piaget \& Vgotsky. Education Psychological Review. 20, 373-389. DOI:10.10007/s10648-008-9079-2.

Garner, R., \& Alexander, P. A. (1989). Metacognition: Answered and unanswered questions. Educational psychologist, 24(2), 143-158.

Galper, A., Wigfield, A., \& Seefeldt, C. (1997). Head Start parents' beliefs about their children's abilities, task values, and performances on different activities. Child Development, 68(5), 897-907.

Kim, B., Zyromski, B., Mariani, M., Lee, S. M., \& Carey, J. C. (2017). Establishing the Factor Structure of the 18-Item Version of the Junior Metacognitive Awareness Inventory. Measurement and Evaluation in Counseling and Development, 50(1-2), 48-57.

Lemberger, M. E., Selig, J. P., Bowers, H., \& Rogers, J. E. (2015). Effects of the student success skills program on executive functioning skills, feelings of connectedness, and academic achievement in a predominantly Hispanic, low- income middle school district. Journal of Counseling \& Development, 93(1), 25-37.

Livingston, J. (1997). Metacognition: An Overview. State University of New York at Buffalo.

McGillicuddy-DeLisi, A. V. (1980). The role of parental beliefs in the family as a system of mutual influences. Family Relation. 29, 317-323. 
Miller, P.H. (2011). (5th Ed). Theories of Developmental Psychology.New York; Worth Publisher.

Miller, S. A., Manhal, M., \& Mee, L. L. (1991). Parental beliefs, parental accuracy, and children's cognitive performance: A search for causal relations. Developmental Psychology, 27(2), 267.

Miller, S. (1988). Parents belief about children cognitive development. Child development. Vol 58(2).

Mohtari, K. \& Reichard, C. A. (2002). Assessing student's metacognitive awareness of reading strategies. Journal of Educational Psychology.94(2).DOI:10.1037//0022.0663.94.2.

Okagaki, L., \& Sternberg, R. J. (1993). Parental beliefs and children's school performance. Child development, 64(1), 36-56.

Schraw, G., \& Dennison, R. S. (1994). Assessing metacognitive awareness. Contemporary educational psychology, 19(4), 460-475.

Sperling, R.A. Howard, B.C. Miller, L.A., \& Murphy, C.(2002). Measures of children's knowledge and regulation of cognition. Contemporary educational psychology. 27, 51-79. Doi: 10.1006/ceps.2001.1091.

Sperling, R. A., Richmond, A. S., Ramsay, C. M., \& Klapp, M. (2012). The measurement and predictive ability of metacognition in middle school learners. The Journal of Educational Research, 105(1), 1-7.

Steinberg, L. (2005). Cognitive and affective development in adolescence. TRENDS in Cognitive Sciences, 9(2), 70 .

Swanson, H. L. (1990). Influence of metacognitive knowledge and aptitude on problem solving. Journal of educational psychology, 82(2), 306.

Tudge, J.R.H. Mokrova, I., Hatfield, B.E.\& Karnik, R. (2009). Uses and Misuses of Bronfenbrenner's bioecological theory of human development. Journal of family theory and review.Dec 2009:198-210.

Weaver, S.O. (2012). The effect of metacognition strategies on academic achievement, metacognitive awareness, and satisfaction in an undergraduate online education course. Dissertation. University of Alabama. USA.

Veenman, M. V., \& Spaans, M. A. (2005). Relation between intellectual and metacognitive skills: Age and task differences. Learning and individual differences, 15(2), 159-176.

Weaver, S. O. (2012). The effects of metacognitive strategies on academic achievement, metacognitive awareness, and satisfaction in an undergraduate online education course. University of South Alabama.

Winne, P. H., \& Nesbit, J. C. (2010). The psychology of academic achievement. Annual Review of Psychology, 61, 653-678.

Young, A. E. (2010). Explorations of metacognition among academically talented middle and high school mathematics students (Doctoral dissertation). 